\title{
Rate and factors affecting non-exclusive breastfeeding among Thai women under the breastfeeding promotion program
}

This article was published in the following Dove Press journal:

International Journal of Women's Health

26 September 2017

Number of times this article has been viewed

\author{
Sucharat Buttham' \\ Kiattisak Kongwattanakul \\ Natiya Jaturat ${ }^{2}$ \\ Sukree Soontrapa' \\ 'Department of Obstetrics and \\ Gynecology, ${ }^{2}$ Breastfeeding Clinic, \\ Srinagarind Hospital, Faculty of \\ Medicine, Khon Kaen University, \\ Khon Kaen, Thailand
}

Objective: The objective of this study was to assess the rate of non-exclusive breastfeeding and associated factors among Thai women under the Breastfeeding Promotion Program.

Methods: This was a prospective descriptive study that involved term postpartum women who attended the Breastfeeding Clinic at Srinagarind Hospital in Thailand, from April to December 2016. Abstracted data included baseline characteristics, obstetric history, breastfeeding history, problems in breastfeeding at day 3 and 2 weeks, and feeding status at 12 weeks postpartum. Univariate and multivariate logistic regression methods were used to determine significant factors predicting non-exclusive breastfeeding.

Results: Of the 500 postpartum women enrolled in this study, follow-up data at 12 weeks postpartum were available for 368 women (73.6\%). The rate of non-exclusive breastfeeding assessed at 12 weeks postpartum was $26.4 \%$ (95\% CI $21.9 \%-31.2 \%)$. Nipple problems and pain during the first 3 days postpartum and milk storage problems at 2 weeks postpartum were the major reasons for non-exclusive breastfeeding (69.4\% and 59.1\%, respectively). The significant independent factors that predicted these included patients not having confidence in their ability to breastfeed exclusively or not having any intention to do so (OR 7.22; 95\% CI 3.26-14.24), no rooming-in (OR 2.31; 95\% CI 1.04-5.12), and low milk quantity at 2 weeks postpartum (OR 3.75; 95\% CI 1.70-8.29).

Conclusion: The rate of non-exclusive breastfeeding in this study was $\sim 26 \%$, and significant associated factors included having lack of confidence/intention, no rooming-in, and low milk quantity reported at 2 weeks postpartum.

Keywords: exclusive breastfeeding, breastfeeding promotion, pregnancy, predictor, breastfeeding problems

\section{Introduction}

Breastfeeding is a valuable keystone for promoting children's health, as it provides essential and irreplaceable nutrition, which aids in a child's growth and development during the first 2 to 3 years of life. It also serves as the child's first immunization and reduces the risk of diarrhea and respiratory infection, obesity, noncommunicable diseases (notably childhood obesity), cardiovascular disease, diabetes mellitus, and allergies. ${ }^{1-3}$ Exclusive breastfeeding is defined as giving an infant breast milk from within the first hour after birth and for the first 6 months of life without other food or water.

In low-income and middle-income countries, however, only one-third of children younger than 6 months are exclusively breastfed. ${ }^{4}$ According to a 2015 World Health Organization (WHO) report, the rate of exclusive breastfeeding in Thailand from 2007 to 2014 was $12 \%$, which was lower than that reported in a survey conducted
Correspondence: Kiattisak Kongwattanakul

Department of Obstetrics and Gynecology, Faculty of Medicine, Khon Kaen University, I 23 Mittraparp Highway, Khon Kaen 40002, Thailand

Tel +6643363030

Fax +66 43348359

Email kiattisak@kku.ac.th
International Journal of Women's Health 2017:9 689-694

(c) (i) (5) ( 2017 Buttham et al. This work is published and licensed by Dove Medical Press Limited. The full terms of this license are avalable at https://www.dovepress.com/terms.php (c) hereby accept the Terms. Non-commercial uses of the work are permitted without any further permission from Dove Medical Press Limited, provided the work is properly attributed. For permission for commercial use of this work, please see paragraphs 4.2 and 5 of our Terms (https://www.dovepress.com/terms.php). 
from 2006 to 2012 (15\%). ${ }^{5}$ The WHO and United Nations Children's Fund has set a goal that at least $50 \%$ of infants be breastfed exclusively for 6 months in $2025 .{ }^{6}$

The Breastfeeding Clinic at Srinagarind Hospital was established as a healthcare unit responsible for promoting exclusive breastfeeding in our institute. Educational sessions regarding breastfeeding are conducted by specialized nurses during antenatal visits. This includes initiation of breastfeeding after birth, practices of rooming-in (mother and infant being placed together in the same room after birth throughout hospitalization), and skin-to-skin contact. However, the rate of non-exclusive breastfeeding in our center and its associated factors have not been evaluated.

The objective of the present study was to assess these variables among Thai women under the Breastfeeding Promotion Program at various periods of time. The findings from this study would be helpful in establishing proper management protocol and identifying any areas of exclusive breastfeeding promotion that need to be improved.

\section{Materials and methods}

This study was a prospective study involving 500 postpartum women who attended the Breastfeeding Clinic from April 2016 to December 2016. Women with HIV infection or whose infant was born with anomalies were excluded, as were those whose infant was transferred to the neonatal intensive care unit (which would preclude the feasibility of exclusive breastfeeding), and women under 20 years of age were legally able to provide consent on their own behalf. Abstracted data included baseline characteristics (age, parity, occupation, monthly income, obstetric history), gestational age, induction/augmentation of labor, mode of delivery, infant birth weight, breastfeeding history, confidence/intention regarding exclusive breastfeeding, average skin-skin contact time, rooming-in, onset of lactation, problems breastfeeding at day 3 and 2 weeks postpartum, and feeding status at 12 weeks postpartum. All postpartum women were evaluated with face-to-face interview at every visit by a specialized nurse at the breastfeeding clinic. Participants who did not appear for their scheduled visits were interviewed about their breastfeeding practices through telephone.

The main breastfeeding problems encountered in this study were divided into eight categories, as follows: 1) infant feeding difficulty was defined as problems with latch, infant drowsiness, going too long between feedings, the infant refusing to breastfeed/nipple confusion, the infant being fussy or frustrated at the frequency or length of breastfeeding, the infant not feeding properly, and other difficulties feeding at the breast; 2) low milk quantity was defined as inadequate maternal production or milk supply, the infant not getting enough milk or unsure if it is getting enough milk, and the infant showing signs of hunger; 3) lack of breastfeeding ability was defined as problems with breastfeeding technique, positioning, or adjusting to breastfeeding; wanting someone else to feed the infant, being tired or exhausted, being uncomfortable with the act or connotations of breastfeeding, and other uncertainties regarding breastfeeding ability as evaluated by specialist nurses; 4) nipple problems and pain was defined as painful nipples, general or unspecified breastfeeding pain, sore breasts, engorgement, breast pain, mastitis or other breast infection, and biting; 5) mother/ infant separation was defined as reduction or cessation of breastfeeding due to work, school, or medical issues; 6) milk storage problem was defined as lack of knowledge regarding milk preservation or an inability to breastfeed when needed; 7) alternate feeding milks was defined as the use of milk formula or other foods; and 8) too much milk was defined as a strong milk ejection reflex, let-down reflex, leaking during feeding, or overfeeding.

The characteristics of all pregnant women were summarized as number (percentage), mean, or median \pm standard deviation. Variables potentially associated with non-exclusive breastfeeding according to univariate analysis $(P<0.20)$, including parity status, history of previous exclusive breastfeeding, confidence/intention regarding exclusive breastfeeding, mode of delivery, onset of lactation, rooming-in, time to first skin-skin contact, and problems breastfeeding, were included in a stepwise logistic regression analysis to determine which, if any, were jointly important in predicting non-exclusive breastfeeding. ${ }^{7}$ Statistical analysis was carried out by using STATA version 10 (StataCorp LP, College Station, TX, USA).

This study was approved by the Ethics Committee of Khon Kaen University. Written informed consent was obtained from all participants (HE591101).

\section{Results}

Of the 500 postpartum women enrolled in this study, data for assessing the outcomes at 2, 6, and 12 weeks postpartum were available in 416 cases $(83.2 \%), 370$ cases $(74 \%)$, and 368 cases $(73.6 \%)$, respectively. Table 1 shows the demographic characteristics of the participants. Twenty-five participants $(6.8 \%)$ were $<20$ years of age. The majority of participants were primigravida $(229 ; 63.3 \%)$ and had middle to high income $(334 ; 90.7 \%)$. One hundred and fifty-two participants $(42.9 \%)$ underwent induction or augmentation of 
Table I Baseline characteristics of the 368 postpartum women

\begin{tabular}{|c|c|}
\hline Characteristics & n (\%) \\
\hline \multicolumn{2}{|l|}{ Age (years) } \\
\hline$<20$ & $25(6.8)$ \\
\hline $20-34$ & $300(81.5)$ \\
\hline$\geq 35$ & $43(11.7)$ \\
\hline \multicolumn{2}{|l|}{ Parity } \\
\hline Nulliparous & $233(63.3)$ \\
\hline Multiparous & I35 (36.7) \\
\hline \multicolumn{2}{|l|}{ Income per month } \\
\hline$<300$ USD & $34(9.3)$ \\
\hline $300-1,000$ USD & $194(52.7)$ \\
\hline$>1,000$ USD & $140(38)$ \\
\hline \multicolumn{2}{|l|}{ History of previous breastfeeding ${ }^{a}$} \\
\hline Exclusive breastfeeding & $69(51.1)$ \\
\hline Non-exclusive breastfeeding & $66(48.9)$ \\
\hline \multicolumn{2}{|c|}{ Reporting confidence in the ability to breastfeed exclusively } \\
\hline$\geq 6$ months & $268(72.8)$ \\
\hline$<6$ months & $100(27.2)$ \\
\hline \multicolumn{2}{|c|}{ Reporting an intention to breastfeed exclusively } \\
\hline$\geq 6$ months & $226(61.4)$ \\
\hline$<6$ months & $142(38.6)$ \\
\hline \multicolumn{2}{|l|}{ Modes of delivery } \\
\hline Normal delivery & $207(56.2)$ \\
\hline Cesarean section & $161(43.8)$ \\
\hline \multicolumn{2}{|l|}{ Birth weight } \\
\hline$<2,500 \mathrm{~g}$ & $23(6.37)$ \\
\hline $2,500-3,500 \mathrm{~g}$ & $288(78.3)$ \\
\hline$>3,500 \mathrm{~g}$ & $57(15.5)$ \\
\hline \multicolumn{2}{|l|}{ Time to first skin-skin contact } \\
\hline Within 60 minutes & I 48 (40.2) \\
\hline$>60$ minutes & $220(59.8)$ \\
\hline \multicolumn{2}{|l|}{ Average time of skin-skin contact } \\
\hline$>4$ hours/day & I53 (4I.6) \\
\hline 4-12 hours/day & $198(53.8)$ \\
\hline$>12$ hours/day & $17(4.6)$ \\
\hline \multicolumn{2}{|l|}{ Rooming-in } \\
\hline Yes & $320(87.0)$ \\
\hline No & $48(13.0)$ \\
\hline \multicolumn{2}{|l|}{ Onset of lactation } \\
\hline$<24$ hours & $126(34.2)$ \\
\hline$\geq 24$ hours & $242(65.8)$ \\
\hline
\end{tabular}

Note: ${ }^{\text {an }}$ multiparous women.

labor. The rate of cesarean section in this study was $43.8 \%$. Low birth weight $(<2,500 \mathrm{~g})$ was noted in $6.37 \%$ of cases. The rate of skin-skin contact within 60 minutes after birth was $40.2 \%$. Infants were roomed-in in the majority of cases (320 participants; $87 \%$ ). Approximately half of participants (53.8\%) reported an average skin-skin contact time of 4-12 hours per day.

Table 2 displays the practices of breastfeeding that changed over the course of the patients' follow-up visits. The rates of non-exclusive breastfeeding were $1.4 \%, 18.7 \%$, and $26.4 \%$ at 2,6 , and 12 weeks postpartum, respectively.
Table 2 Number and rate of women practicing exclusive and non-exclusive breastfeeding during the postpartum period

\begin{tabular}{|c|c|c|c|}
\hline \multirow[t]{3}{*}{ Type of breastfeeding } & \multicolumn{3}{|c|}{ Postpartum period, n (\%) } \\
\hline & 2 weeks & 6 weeks & 12 weeks \\
\hline & $n=416$ & $n=370$ & $n=368$ \\
\hline Non-exclusive breastfeeding & $6(1.4)$ & $69(18.7)$ & $97(26.4)$ \\
\hline Mixed breastfeedinga & $6(1.4)$ & $52(14.0)$ & $68(18.5)$ \\
\hline Stopped breastfeeding ${ }^{\mathrm{b}}$ & $0(0)$ & $17(4.6)$ & $29(7.9)$ \\
\hline
\end{tabular}

Notes: aMixed breastfeeding: feeding an infant breast-milk with infant formula, food, or water; bstopped breastfeeding: feeding only with infant formula, food, or water.

Table 3 describes the problems regarding breastfeeding practice at 3 days and 2 weeks postpartum. The three most predominant problems at 3 days postpartum was nipple problems and pain (69.4\%), followed by the lack of breastfeeding ability (65.4\%), and infant feeding difficulty (56.4\%). At 2 weeks postpartum, breastfeeding problems were distributed relatively equally throughout the following categories: milk storage problems (59.1\%), lack of breastfeeding ability (54.8\%), infant feeding difficulty (51\%), and nipple problems and pain $(49.5 \%)$.

Univariate analysis was used to test variables potentially associated with non-exclusive breastfeeding at 12 weeks postpartum including parity, history of previous breastfeeding, confidence/intention regarding exclusive breastfeeding, mode of delivery, first skin-skin contact time, average time of skin-skin contact, rooming-in, onset of lactation, and various problems (divided into eight main categories). Factors with a $P$-value of $<0.2$, including parity (nulliparous vs multiparous), history of previous breastfeeding (exclusive vs non-exclusive), confidence/intention regarding exclusive breastfeeding (yes or no), mode of delivery (cesarean or vaginal delivery), rooming-in (yes or no), onset of lactation ( $<24$ or $\geq 24$ hour), and low milk quantity problem at

Table 3 Problems regarding breastfeeding practice in the early period following delivery

\begin{tabular}{lll}
\hline Problems with & \multicolumn{2}{l}{ Postpartum period } \\
\cline { 2 - 3 } breastfeeding & 3 days & 2 weeks \\
\hline Postpartum women & 500 & 416 \\
Nipple problems and pain & $347(69.4)$ & $206(49.5)$ \\
Lack of breastfeeding ability & $327(65.4)$ & $228(54.8)$ \\
Infant feeding difficulty & $283(56.4)$ & $212(5 \mathrm{I} .0)$ \\
Low milk quantity & I65 (33.0) & $56(13.5)$ \\
Alternate feeding milks & I07 (2I.4) & $60(14.4)$ \\
Milk storage problems & NA & $246(59.1)$ \\
Too much milk & NA & $167(40.1)$ \\
Mother/infant separation & NA & $12(2.9)$ \\
\hline Note: &
\end{tabular}

Note: ${ }^{a}$ Data are presented as number (percentage).

Abbreviation: NA, not applicable. 
Table 4 Predictors of non-exclusive breastfeeding at 12 weeks postpartum

\begin{tabular}{|c|c|c|c|c|c|c|}
\hline \multirow[t]{2}{*}{ Variable } & \multirow{2}{*}{$\begin{array}{l}\text { Total number } \\
\text { of women }\end{array}$} & \multirow{2}{*}{$\begin{array}{l}\text { Number of } \\
\text { non-exclusive } \text { BF }^{a}\end{array}$} & \multicolumn{2}{|c|}{ Univariate analysis } & \multicolumn{2}{|l|}{ Multivariate analysis } \\
\hline & & & OR $(95 \% \mathrm{CI})$ & $P$-value & Adjusted OR (95\% Cl) & $P$-value \\
\hline \multicolumn{4}{|l|}{ Parity } & 0.005 & & 0.290 \\
\hline Primiparous & 229 & $72(31.4)$ & $2.09(1.25-3.50)$ & & $4.00(0.31-52.23)$ & \\
\hline Multiparous & 139 & $25(18.0)$ & & & & \\
\hline \multicolumn{3}{|c|}{ History of previous breastfeeding } & & 0.013 & & 0.119 \\
\hline Non-exclusive BF & 69 & $18(26.1)$ & $3.53(1.30-9.56)$ & & $2.39(0.79-7.16)$ & \\
\hline Exclusive BF & 66 & $6(9.1)$ & & & & \\
\hline \multicolumn{4}{|c|}{ Confidence in/intention to BF exclusively } & 0.000 & & $<0.001$ \\
\hline No & 212 & $28(13.2)$ & $5.45(3.05-9.76)$ & & $7.22(3.26-14.24)$ & \\
\hline Yes & 86 & $39(45.3)$ & & & & \\
\hline \multicolumn{3}{|l|}{ Mode of delivery } & & 0.185 & & 0.611 \\
\hline Cesarean delivery & 161 & $48(29.8)$ & $1.37(0.86-2.18)$ & & I. $16(0.66-2.05)$ & \\
\hline Vaginal delivery & 207 & $49(23.7)$ & & & & \\
\hline \multicolumn{3}{|l|}{ Rooming-in } & & 0.063 & & 0.039 \\
\hline No & 48 & $18(37.5)$ & $1.83(0.97-3.46)$ & & $2.31(1.04-5.12)$ & \\
\hline Yes & 320 & $79(24.7)$ & & & & \\
\hline \multicolumn{3}{|l|}{ Onset of lactation } & & 0.008 & & 0.244 \\
\hline$\geq 24$ hours & 126 & $44(34.9)$ & $1.91(1.19-3.08)$ & & I.4I (0.79-2.50) & \\
\hline$<24$ hours & 242 & $53(21.9)$ & & & & \\
\hline \multicolumn{3}{|c|}{ Low milk quantity problems at two weeks } & & $<0.001$ & & 0.001 \\
\hline Yes & 48 & $24(50)$ & $3.38(|.8|-6.3 \mid)$ & & $3.75(1.70-8.29)$ & \\
\hline No & 320 & $73(22.8)$ & & & & \\
\hline
\end{tabular}

Note: aData are presented as number (percentage).

Abbreviations: $\mathrm{Cl}$, confidence interval; $\mathrm{OR}$, odds ratio; $\mathrm{BF}$, breastfeeding.

2 weeks postpartum (yes or no), were subsequently included in the multivariate analysis. This analysis identified the following significant independent factors as predicting non-exclusive breastfeeding status at 12 weeks postpartum: lack of confidence/intention regarding exclusive breastfeed (adjusted OR 7.22, 95\% CI 3.26-14.24), not rooming-in (adjusted OR 2.31, 95\% CI 1.04-5.12), and low-milk quantity problems at 2 weeks postpartum (adjusted OR 3.75, 95\% CI 1.70-8.29) (Table 4).

\section{Discussion}

In this study, the authors prospectively evaluated postpartum women participating the Srinagarind Hospital Breastfeeding Promotion Program. The rate of non-exclusive breastfeeding assessed at 12 weeks after delivery was $26.4 \%$. In addition, we were able to highlight three significant factors affecting the rate of non-exclusive breastfeeding including lack of confidence/intention regarding exclusive breastfeeding, not rooming-in, and low milk quantity.

According to a 2013 WHO report, the global rate of nonexclusive breastfeeding at 6 months was $62 \%{ }^{6}$ The rate of non-exclusive breastfeeding varies across the geographic regions. According to data from the WHO, the reported rate of non-exclusive breastfeeding in Europe from 1998 to 2013 was $67 \%$ and $77 \%$ at 4 and 6 months, respectively. ${ }^{8}$
In North America, the rate of non-exclusive breastfeeding at 4 months was $39.5 \%$ in $2014 .{ }^{9}$ In Asian countries, rates of non-exclusive breastfeeding at 12 weeks range between $38 \%$ and $43 \%{ }^{10,11}$ In this study, the rate of non-exclusive breastfeeding was $26.4 \%$ (95\% CI $21.9 \%-31.2 \%$ ), which was considerably low when compared with other settings. This might result from breastfeeding promotion, breastfeeding education being provided during antenatal visits to all pregnant/postpartum women by specialized nurses, immediate initiation of breastfeeding with skin-to-skin contact after birth in the labor room, and rooming-in routinely practiced at in our institute.

Previous studies have reported that the intention to breastfeed exclusively during the prenatal period has a significant impact on exclusive breastfeeding practice. For example, Perrine et $\mathrm{al}^{12}$ noted that only $32.4 \%$ of mothers who intended to breastfeed exclusively for 3 months or more followed through on this goal. However, mothers who were married and multiparous were more likely to follow through on their intention to breastfeed exclusively. In this study, confidence/ intention regarding exclusive breastfeeding were major factors that impacted whether mothers engaged in exclusive breastfeeding (adjusted OR 7.22, 95\% CI 3.26-14.24). If women are given breastfeeding education during the antenatal period, breastfeeding care, and help from specialized 
nurses during the early postpartum period, it may increase their confidence in their ability to properly breastfeed and lead to exclusive breastfeeding.

The impact of rooming-in on the practice of breastfeeding remains inconclusive. In our study, rooming-in was a significant independent predictor of exclusive breastfeeding (adjusted OR 2.31, 95\% CI 1.04-5.12). These findings are similar to those of Ward et al, ${ }^{13}$ who noted that rooming-in and skin-to-skin after delivery significantly increased the proportion of mothers who engaged in exclusive breastfeeding from $37 \%$ to $59 \%$. However, these findings were contrary to those of other previous studies. For example, Cochrane conducted a review to assess the effect of rooming-in on the proportion of mothers who practiced exclusive breastfeeding and found no difference at 4 months between the rooming-in group and separation group. ${ }^{14}$ In our opinion, however, the mother and infant being together in the same room can result in the initiation of breastfeeding, early skin-to-skin contact, prolonged duration of breastfeeding, and a supportive environment in which questions regarding latching and other aspects of breastfeeding can be answered. This kind of support can be crucial when mother has to care for her baby at home after discharge form the hospital.

Problems in breastfeeding during the postpartum period have been reported to lead to increased probability of nonexclusive breastfeeding. Wagner et al, ${ }^{15}$ for example, reported that breastfeeding concerns and problems, particularly infant feeding and milk quantity problems occurring within the first 2 weeks postpartum, were highly prevalent and were associated with an up to nine-fold greater risk of stopping breastfeeding earlier than intended. This finding is similar to those of our study in that women with low milk quantity during the first 2 weeks postpartum were more likely to report non-exclusive breastfeeding (adjusted OR 3.75, 95\% CI 1.70-8.29). A possible explanation for this is that women with low milk quantity might have other problems, as well, such as nipple problems and pain, lack of breastfeeding ability, or infant feeding difficulty, resulting in a high rate of non-exclusive breastfeeding.

However, this study has several limitations. First, this study had a considerably high rate of loss to follow up (132 cases; $26.4 \%$ ), which may have influenced the findings. The majority of women felt inconvenient to visit our hospital so they followed up at local hospitals instead, and the postpartum women could not be reached by phone call. Second, the population who participated in this study consisted only of women with term delivery in a single tertiary-care institution, which might limit the generalizability of the results to other populations and settings. Finally, this study evaluated breastfeeding status only up to 12 weeks postpartum. Thus, the results could not be compared to other studies with longer evaluation times.

Despite these limitations, this was a prospective study that evaluated the problems or factors related to non-exclusive breastfeeding at various periods of time, which might be helpful for designing appropriate management protocol specific to each time period. Moreover, such knowledge can pave the way for further study or intervention in order to increase the rate of exclusive breastfeeding in our setting.

\section{Conclusion}

The rate of non-exclusive breastfeeding assessed at 12 weeks postpartum was $26.4 \%$. Significant factors affecting the rate of non-exclusive breastfeeding included lack of confidence/ intention regarding the practice of exclusive breastfeeding, not rooming-in, and low milk quantity, as reported at 2 weeks postpartum. As the lack of confidence regarding breastfeeding or intention to do so was the strongest predictor for non-exclusive breastfeeding in our setting, further research to design effective interventions (such as a support program for postpartum women aimed at improving these factors) are warranted.

\section{Acknowledgments}

We thank the patients for their participation and the staff at Srinagarind Hospital for their assistance. We also thank Mr Dylan Southard, English Consultant, Research Affairs, Faculty of Medicine, Khon Kaen University for his assistance with the English-language presentation of the manuscript.

\section{Disclosure}

The authors report no conflicts of interest in this work.

\section{References}

1. Patel R, Oken E, Bogdanovich N, et al. Cohort profile: the promotion of breastfeeding intervention trial (PROBIT). Int J Epidemiol. 2014; 43(3):679-690.

2. Lauer JA, Betrán AP, Barros AJD, de Onís M. Deaths and years of life lost due to suboptimal breast-feeding among children in the developing world: a global ecological risk assessment. Public Health Nutr. 2006; 9(6):673-685.

3. Edmond KM, Zandoh C, Quigley MA, Amenga-Etego S, OwusuAgyei S, Kirkwood BR. Delayed breastfeeding initiation increases risk of neonatal mortality. Pediatrics. 2006;117(3):e380-e386.

4. Victora CG, Bahl R, Barros AJD, et al. Breastfeeding in the 21st century: epidemiology, mechanisms, and lifelong effect. Lancet Lond Engl. 2016;387(10017):475-490.

5. World Health Organization. World Health Statistics 2014. Geneva: World Health Organisation. Available from: http://www.who.int/gho/publications/ world_health_statistics/2014/en/. Accessed September 20, 2017. 
6. World Health Organization. Global Targets 2025. To Improve Maternal, Infant and Young Child Nutrition. Available from: http://www.who.int/ nutrition/topics/nutrition_globaltargets2025/en/. Accessed 6 October 2014.

7. Altman DG. Relation between several variables. In: Altman DG, editor. Practical Statistics for Medical Research. London: Chapman and Hall; 1991.

8. Bagci Bosi AT, Eriksen KG, Sobko T, Wijnhoven TM, Breda J. Breastfeeding practices and policies in WHO European Region Member States. Public Health Nutr. 2016;19(4):753-764.

9. Laliberté C, Dunn S, Pound C, et al. A randomized controlled trial of innovative postpartum care model for mother-baby dyads. PLoS One. 2016;11(2):e0148520.

10. Kim BY. Factors that influence early breastfeeding of singletons and twins in Korea: a retrospective study. Int Breastfeed J. 2016;12:4.
11. Inoue M, Binns CW, Otsuka K, Jimba M, Matsubara M. Infant feeding practices and breastfeeding duration in Japan: a review. Int Breastfeed J. 2012;7(1):15.

12. Perrine CG, Scanlon KS, Li R, Odom E, Grummer-Strawn LM. Baby-friendly hospital practices and meeting exclusive breastfeeding intention. Pediatrics. 2012;130(1):54-60.

13. Ward LP, Williamson S, Burke S, Crawford-Hemphill R, Thompson AM. Improving exclusive breastfeeding in an urban academic hospital. Pediatrics. 2017;139(2).

14. Jaafar SH, Ho JJ, Lee KS. Rooming-in for new mother and infant versus separate care for increasing the duration of breastfeeding [review]. Cochrane Database Syst Rev. 2016;(8):CD006641.

15. Wagner EA, Chantry CJ, Dewey KG, Nommsen-Rivers LA. Breastfeeding concerns at 3 and 7 days postpartum and feeding status at 2 months. Pediatrics. 2013;132(4):e865-e875.
International Journal of Women's Health

\section{Publish your work in this journal}

The International Journal of Women's Health is an international, peerreviewed open-access journal publishing original research, reports, editorials, reviews and commentaries on all aspects of women's healthcare including gynecology, obstetrics, and breast cancer. The manuscript management system is completely online and includes

\section{Dovepress}

a very quick and fair peer-review system, which is all easy to use. Visit http://www.dovepress.com/testimonials.php to read real quotes from published authors. 